\title{
Safety and efficacy of tocilizumab for rheumatoid arthritis: a systematic review and meta-analysis of clinical trial studies
}

\author{
Amal Saki ${ }^{1}$ ID , Elham Rajaei² ID , Fakher Rahim $^{3}$ ID \\ ${ }^{1}$ Department of Biostatistics and Epidemiology, School of Public Health, Ahvaz Jundishapur University of Medical Sciences, Ahvaz, Iran \\ 2Department of Rheumatology, Golestan Hospital, Ahvaz Jundishapur University of Medical Sciences, Ahvaz, Iran \\ ${ }^{3}$ Research Center of Thalassemia and Hemoglobinopathies, Health Research Institute, Ahvaz Jundishapur University of Medical \\ Sciences, Ahvaz, Iran
}

\begin{abstract}
The present systematic review and meta-analysis was conducted to assess the effect of tocilizumab (TCZ) in patients with rheumatoid arthritis (RA). We systematically searched all potential articles in the main databases, including PubMed, Scopus, EMBASE, Web of Sciences (ISI), and Cochrane Center. The search was subsequently updated in December 2020. The initial review and extraction of information were performed independently by two authors to collect the first author and publication year; sample size; mean age of the intervention and control groups; the dose of TCZ, and the follow-up duration. Outcomes of interest include the ACR20, ACR50, ACR70, total complication rate, and the occurrence of remission. Any disagreements between the reviewers were resolved by discussion and re-check of the article and consultation with a third reviewer. After reviewing and culling, 15 clinical trials comparing the clinical efficacy of TCZ and its comparators in the treatment of patients with RA entered the qualitative and quantitative synthesis. Tocilizumab $8 \mathrm{mg}$ was statistically better than $4 \mathrm{mg}$ or placebo for ACR responses. Significant clinical adverse events in patients with RA treated with TCZ, such as abnormal liver function tests (LFTs) and infections, were more frequent than in comparator groups. This systematic review and meta-analysis suggest that the combination therapy of TCZ with other drugs such as methotrexate and disease-modifying antirheumatic drugs has been studied for various clinical effects concerning safety and clinically significant adverse events. Although the data are promising, long-term performance and safety data need to be fully identified, as well as the risks and benefits of TCZ, especially appropriate timing, dosage, and regimen.
\end{abstract}

Key words: adverse events, efficacy, safety, meta-analysis, rheumatoid arthritis, adverse events, tocilizumab.

\section{Introduction}

Rheumatoid arthritis (RA) is an autoimmune and long-term systemic inflammatory disorder that can cause inflammation in the lining of a person's joints. Rheumatoid arthritis is considered as an unidentified event or a mixture of conditions that causes synovial inflammation, which leads to stiffness, soft-tissue edema, and pain [1]. Some people with RA often experience wide-range damage to body systems, including the skin, eyes, lungs, heart, and arteries [1].
Rheumatoid arthritis is the leading cause of disability worldwide, affecting one in every 100 people, according to the World Health Organization (WHO), and about half of adults with the autoimmune disorder are said to be unable to do full-time work within 10 years of being diagnosed. In RA, the body's immune system attacks the lining of the joint capsule - the hard membrane that covers the various parts of the joint; thus, the disease process can eventually destroy cartilage and bone at the joint site [1]. 
Scientists have not yet found the cause of immune system changes in RA, but factors such as genetic factors, environmental factors such as viral and bacterial infections (genetically predisposed people), hormonal factors, etc. are involved in their genesis. Multiple genetic and environmental factors that increase the risk of developing RA include family history, age, gender, previous joint injury, and obesity [2].

A group of researchers believes that sudden climate change has a significant effect on the severity of RA, but so far it has not been proven that climate change is effective in reducing the effects of this disease [3, 4]. Diagnosis of RA in the early stages of the disease is difficult for several reasons.

First, there is no specific test to diagnose the disease; besides, the symptoms can also be similar to other than RA types of arthritis [5].

Therefore, physicians use a variety of diagnostic methods, such as medical history, physical examination, laboratory tests, and X-rays (to determine the degree of joint damage). Rheumatoid arthritis occurs in all ethnicities and age groups [6], and is about two to three times more common in women than in men [7].

In the treatment of RA, conventional anti-rheumatic drugs controlling the disease are preferred and should be started immediately after the diagnosis, within 3 months after the onset of persistent symptoms [8]. This family of drugsincludes methotrexate, leflunomide, hydroxychloroquine, minocycline, and sulfasalazine. Nonsteroidal antiinflammatory drugs (NSAIDs) and glucocorticoids are effective in the general and functional recovery of the patient and are especially used in relapses and as a bridge between courses of anti-rheumatic drugs to control the disease.

At the early stages, starting treatment with rest and movement balance training and referral to supportive social centers is recommended, then starting medical treatment using salicylates or non-steroidal antiinflammatory agents (NSAIDs) with anti-inflammatory and analgesic effects at full dose [9]. The use of COX-2 cyclooxygenase inhibitors, new drugs from NSAIDs, inhibiting the inflammatory process, and ultimately having less toxic effects, has been suggested [10].

Most patients with RA use painkillers and antiinflammatory drugs, and some medications also reduce the destructive process of the disease [11]. The treatment for RA has changed over the last decades. The main goal of treatment of this disease has always been to maintain a person's functional abilities.

During the last decade, the American College of Rheumatology and the European League Against Rheumatism (EULAR) have attempted to introduce new and more comprehensive treatments for $\operatorname{RA}[12,13]$.
Biological drugs for the treatment of RA target specific cells that play an important role in the immune system; however, with more careful efforts and disease management in these patients, a reduction in bone and cartilage destruction of the joints is often seen [14].

Tocilizumab (TCZ) is an immunosuppressive drug used mainly for RA and widespread idiopathic arthritis treatment [15]. Tocilizumab is an interleukin 6 (IL-6) inhibitor, which is a type of cytokine that plays a vital role in the human immune system, but its overproduction and activity cause autoimmune diseases, and in some diseases, including some cancers and coronary heart disease, it causes damage to body tissues [16].

So far, exists a single systematic review/metaanalysis on treatment with TCZ in RA [17]. Studies included in this meta-analysis were published before 2016 and the literature databases searched were limited. Besides, Teitsma et al. [17] just synthesized the findings on TCZ as monotherapy or combination therapy, and the studies published during nearly 5 years (2016-2020) and some studies in other databases such as Scopus and Web of Science (ISI) need to be included and reanalyzed, to observe whether the results have changed.

To date, several studies have suggested that this drug is effective in treating RA, but no consistent consequences were reported among these studies [18, 19]; therefore, this systematic review and meta-analysis was conducted to assess the effect of TCZ in patients with RA.

\section{Material and methods}

This systematic review protocol and data extraction were conducted following the preferred reporting items for systematic reviews and meta-analyses (PRISMA) [20], and the Cochrane Handbook of Systematic Reviews of Interventions [21].

\section{Search strategy}

All potential articles were initially identified through a systematic search in main databases, including PubMed, Scopus, EMBASE, ISI Web of Sciences and Cochrane Center using MeSH key words, including "tocilizumab", "RHPM-1", "RG-1569”, "R-1569", "MSB11456”, "MSB11456”, "monoclonal antibody, MRA”, “RO-4877533”, "actemra”, "roactemra”, "atlizumab”, "sarilumab”, "kevzara", "siltuximab", "sylvan”, and "rheumatoid arthritis" or "arthritis, rheumatoid" [MeSH]".

Further search for relevant studies was performed through the reference lists of the selected and review articles. Also, additional records were identified through searching medRxiv, bioRxiv, Research square, and Social Science Research Network (SSRN). The search was not restricted by language. The most recent or complete 
report was used when multiple reports were published describing the same sample. The search was subsequently updated in December 2020.

\section{Study selection}

Studies on patients 18 years of age and older with active RA comparing the clinical efficacy of TCZ and its comparators were selected. Inclusion criteria were patients with RA according to the American College of Rheumatology (ACR) 1987 modified criteria; intervention, use of TCZ; comparison, American College of Rheumatology 20\%, 50\%, and 70\% improvement criteria ACR20, ACR50, ACR70, respectively, overall complication rate; and study design, randomized controlled trial (RCT). We excluded articles in different formats such as reviews, case reports, short communications, letters or opinions, as well as studies in which an animal model was used.

\section{Data extraction}

The initial review and extraction of information were performed independently by two authors (FR and ER) to collect the first author and publication year; sample size; mean age of the intervention and control groups; the dose of TCZ; and the follow-up duration. Outcomes of interest including the ACR20, ACR50, ACR70, total complication rate, and the occurrence of remission were recorded. Any disagreements between the reviewers were resolved by discussion and re-check of the article and consultation with a third reviewer (ASM).

\section{Methodological quality and bias assessment}

The risk of bias (ROB) for every single study was evaluated using the Cochrane Collaboration's tool, which has 7 categories: random sequence generation-defining selection bias, allocation concealment defining selection bias, blinding of participants and personnel defining performance bias, blinding of outcome assessment defining detection bias, incomplete outcome data defining attribution bias, selective reporting defining reporting bias, and other bias [22].

The quality assessment findings were revealed as one of the three pre-specified categories: including low, unclear, and high. The publication bias was measured qualitatively using the funnel plot.

\section{Statistical analysis}

The number of clinical responses ACR20, ACR50, ACR70, and remission patients as well as DAS28 (good) and DAS28 (good or moderate) per treated and control groups of patients were used to calculate the odds ratio
(OR). The odds ratio and its 95\% confidence intervals (CI) were calculated to assess the improvement and clinical efficacy of TCZ versus comparators in the treatment of patients with RA.

The heterogeneity and inconsistency were evaluated using Cochrane Q and $R^{2}$ statistics, respectively [23]. The $p$-value $<0.01$ was considered as indicating significant heterogeneity. Furthermore, $R^{2}<25 \%$ showed homogeneity between studies, and $R^{2}>50 \%$ showed high heterogeneity [23].

According to the results of the heterogeneity test, either DerSimonian and Laird's random-effects method or Mantel-Haenszel's fixed-effects method was used to estimate the overall OR and 95\% confidence intervals [24, 25].

Moreover, subgroup analysis was performed based on the dose (4 mg, $8 \mathrm{mg}$ ), type of TCZ group (TCZ, TCZ + MTX and TCZ + DMARD) and follow-up time (less than or equal to 24 weeks and more than 24 weeks) as an important variable which may cause heterogeneity between studies.

Egger's regression test was implemented to assess small study effects due to potential publication bias. Statistical analysis was performed using STATA 16 software (STATA Corporation, College Station, Texas).

\section{Results}

\section{Characteristics of the studies}

The initial search yielded 25,869 potentially relevant studies, of which following the exclusion of 17,117 duplicate articles, 8,752 studies were subsequently evaluated. Then, 835 articles were recognized for full-text screening according to pre-defined eligibility criteria when eliminating the rest of the 7,917 studies by title/ abstract.

Finally, 821 articles were excluded after the full-text screening, and only 15 clinical trials comparing the clinical efficacy of TCZ and its comparators in the treatment of patients with RA entered qualitative and quantitative synthesis (Fig. 1).

Overall, this systematic review and meta-analysis involved a total of 10,314 patients with RA, including 5,639 in the TCZ group and 3,986 in the comparator group. The characteristics of included studies are given in detail in the supplementary materials* (Table SI).

Of the 15 studies, all except one [26] compared TCZ with placebo [26-40]. All selected studies except one

*Supplementary materials are available for free in the on-line version of the format supplied by the authors, and are accessible to the whole readership. The supplement includes figures and tables marked with the letter S. Supplementary materials are not formatted or edited by our editorial team and are published under the responsibility of the authors. 


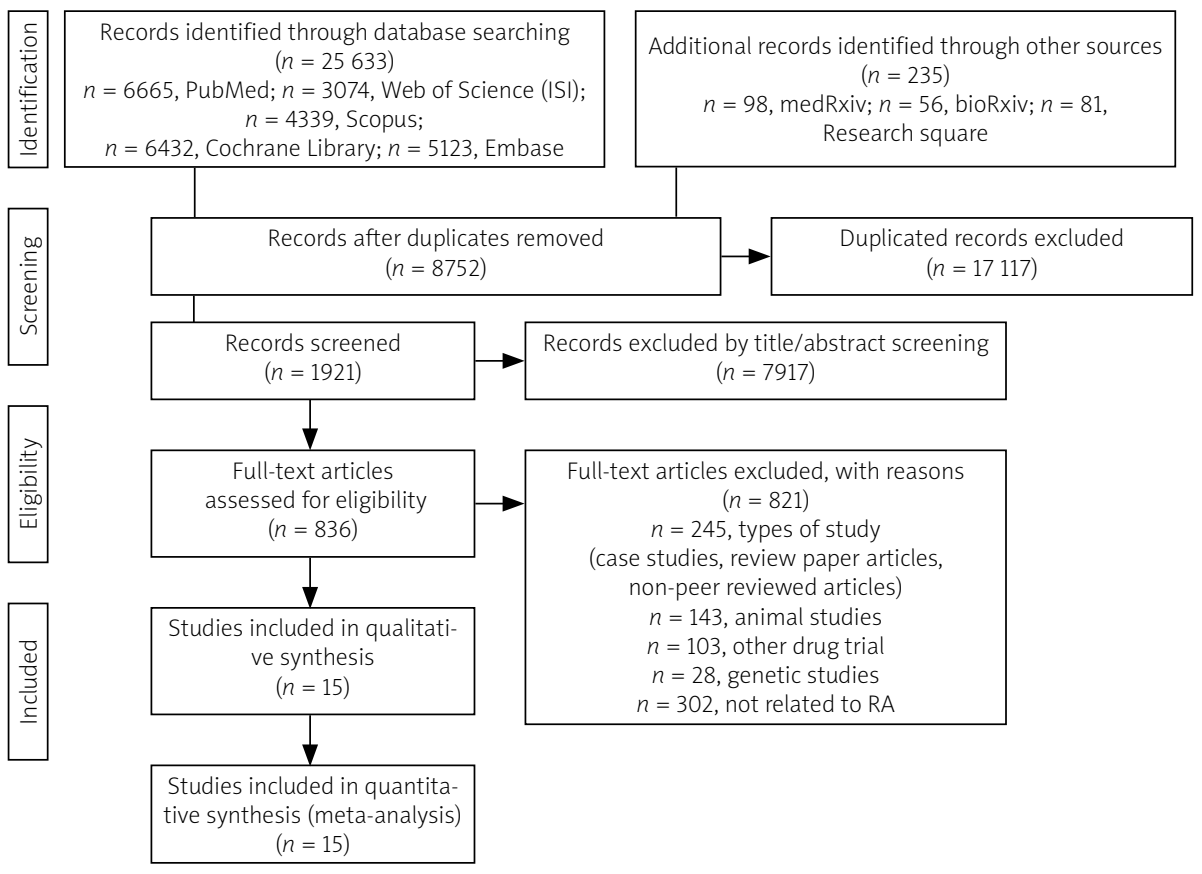

Fig. 1. Results of literature search and evaluation of identified studies according to the Preferred Reporting Items for Systematic Reviews and Meta-analyses (PRISMA) guidelines.

trial [35] used TCZ at 4 and $8 \mathrm{mg} / \mathrm{kg}$ intravenously. Except for one study [30], they were all multicenter trials. Four studies were conducted in the USA [33, 35, 36, 39], two each in Germany [28, 29], and one each in the Netherlands, Japan, France, Australia, South Africa, and the UK [27, 31, 32, 34, 37, 40].

A fixed dose of $8 \mathrm{mg} / \mathrm{kg}$ was the reported regimen of TCZ in nine trials [26, 27, 29-31, 33, 34, 39], fixed doses of $4 \mathrm{mg} / \mathrm{kg}$ and $8 \mathrm{mg} / \mathrm{kg}$ were given in the remaining six studies [28, 32, 36-38, 40], and a single trial used a subcutaneous regimen at a dose of $164 \mathrm{mg}$ [35].

\section{Quality of the evidence}

An overview of the risk of bias per study is presented in Figure 2. In a single further study, information on random sequence generation, blinding of participants and staff, selective reporting, or allocation concealment could not be retrieved, leading to a judgment of unclear risk of bias [30]. In 14 studies, the allocation concealment was adequate and therefore led to a low risk of bias. We found a high risk of detection bias in 3 included studies [30, 31, 40].

However, by considering the dose as an important variable which may cause heterogeneity between studies, subgroup analysis was performed using doses of $4 \mathrm{mg}$ and $8 \mathrm{mg}$. A total of 5 studies with 2214 patients (1117, 1097 assigned to TCZ 4 mg and comparator groups, respectively) and 14 studies in which patients were randomly assigned to TCZ 8 mg or another comparator were included in the meta-analysis. The results of Cochrane $Q$ and $R$ statistics showed that 5 and 14 studies of 4 and $8 \mathrm{mg}$ of TCZ were heterogeneous, so $\mathrm{OR}$ as the main effect size was estimated by using the random effects model (Table II).

The results of Cochrane $\mathrm{Q}$ and $I^{2}$ statistics of clinical efficacy endpoints showed that our studies were heterogeneous with $R^{2}=78-96$ and $p<0.01$, so a weighted estimation of OR was obtained using a random effect model.

The summary estimation of primary and secondary endpoints showed that the significantly high proportion of patients treated by TCZ achieved ACR20/50/70, remission, and DAS28 remission.

American College of Rheumatology 20 with $\mathrm{OR}=2.33$ (95\% Cl: $[1.49 ; 3.66])$ indicated that patients treated with TCZ who achieved ACR2O had an OR of $2.33 \mathrm{com}$ pared with the control group. Also, the OR of remission $(\mathrm{OR}=4.94 ; 95 \% \mathrm{Cl}$ : [3.07; 7.95]) showed the significant clinical effect of TCZ versus other comparators. A total of 8 studies that reported the DAS28 (good) also indicated the significantly higher proportion of DAS28 remission in patients treated with $\mathrm{TCZ}(\mathrm{OR}=8.20 ; 95 \% \mathrm{Cl}$ : [4.99; 13.48]) (Table I).

In all defined sub-groups patients treated with TCZ showed a higher proportion of improvement than comparator groups. However, assessing the pooled estimation of OR of ACR20/50/70 remission and DAS28 
Table I. Overall improvement and clinical efficacy of tocilizumab and its comparators in the treatment of patients with rheumatoid arthritis

\begin{tabular}{|lccccc|}
\hline Response & $n$ & OR $(95 \%$ Cl) & $I^{2}$ & $\begin{array}{c}\chi^{2} \\
(p \text {-value })\end{array}$ & $\begin{array}{c}\text { Egger test } \\
(p \text {-value })\end{array}$ \\
\hline ACR20 & 19 & $2.33(1.49 ; 3.66)$ & 96 & $\begin{array}{c}479.02 \\
(<0.001)\end{array}$ & $\begin{array}{c}2.73 \\
(0.01)\end{array}$ \\
\hline ACR50 & 18 & $2.57(1.68 ; 3.93)$ & 94 & $\begin{array}{c}301.87 \\
(<0.001)\end{array}$ & $\begin{array}{c}3.02 \\
(0.008)\end{array}$ \\
\hline ACR70 & 18 & $3.27(2.04 ; 5.27)$ & 90 & $\begin{array}{c}187.51 \\
(<0.001)\end{array}$ & $\begin{array}{c}4.22 \\
(0.001)\end{array}$ \\
\hline Remission & 17 & $4.94(3.07 ; 7.95)$ & 93 & $\begin{array}{c}254.66 \\
(<0.001)\end{array}$ & $\begin{array}{c}5.01 \\
(0.0002)\end{array}$ \\
\hline DAS28 (good) & 8 & $8.20(4.99 ; 13.48)$ & 78 & $\begin{array}{c}32.15 \\
(<0.001)\end{array}$ & $\begin{array}{c}0.53 \\
(0.61)\end{array}$ \\
\hline DAS28 (good or moderate) & 7 & $5.76(2.51 ; 13.24)$ & 95 & $\begin{array}{c}143.31 \\
(<0.001)\end{array}$ & $\begin{array}{c}1.76 \\
(0.14)\end{array}$ \\
\hline
\end{tabular}

Table II. Subgroup analysis based on dose of tocilizumab and its comparators in the treatment of patients with rheumatoid arthritis

\begin{tabular}{|c|c|c|c|c|c|c|}
\hline Response & $\begin{array}{l}\text { Dose } \\
\text { [mg] }\end{array}$ & $n$ & OR $(95 \% \mathrm{Cl})$ & $P^{2}$ & $\begin{array}{c}\chi^{2} \\
\text { (p-value) }\end{array}$ & $p$-value* \\
\hline \multirow[t]{2}{*}{ ACR20 } & 4 & 5 & $2.48(1.59 ; 3.86)$ & 78 & $\begin{array}{c}18.29 \\
(<0.001)\end{array}$ & 0.78 \\
\hline & 8 & 14 & $2.23(1.25 ; 3.98)$ & 97 & $\begin{array}{c}455 \\
(<0.001)\end{array}$ & \\
\hline \multirow[t]{2}{*}{ ACR50 } & 4 & 5 & $3.25(1.64 ; 6.43)$ & 85 & $\begin{array}{c}27 \\
(<0.001)\end{array}$ & 0.45 \\
\hline & 8 & 13 & $2.34(1.38 ; 3.96)$ & 95 & $\begin{array}{c}270 \\
(<0.001)\end{array}$ & \\
\hline \multirow[t]{2}{*}{ ACR70 } & 4 & 5 & $4.67(1.81 ; 12.07)$ & 76 & $\begin{array}{c}17.17 \\
(<0.001)\end{array}$ & 0.42 \\
\hline & 8 & 13 & $2.97(1.68 ; 5.26)$ & 92 & $\begin{array}{c}165 \\
(<0.001)\end{array}$ & \\
\hline \multirow[t]{2}{*}{ Remission } & 4 & 4 & $4.71(2.45 ; 9.05)$ & 67 & $\begin{array}{c}9.20 \\
(0.03)\end{array}$ & 0.94 \\
\hline & 8 & 13 & $4.86(2.77 ; 8.53)$ & 94 & $\begin{array}{c}233.58 \\
(<0.001)\end{array}$ & \\
\hline \multirow[t]{2}{*}{ DAS28 (good) } & 4 & 2 & $6.78(3.66 ; 12.55)$ & 0 & $\begin{array}{c}<0.001 \\
(0.96)\end{array}$ & 0.59 \\
\hline & 8 & 6 & $8.59(4.72 ; 15.64)$ & 84 & $\begin{array}{c}31.91 \\
(<0.001)\end{array}$ & \\
\hline \multirow[t]{2}{*}{ DAS28 (good or moderate) } & 4 & 2 & $6.57(2.84 ; 15.20)$ & 65 & $\begin{array}{c}2.88 \\
(0.09)\end{array}$ & 0.78 \\
\hline & 8 & 5 & $5.42(1.81 ; 16.22)$ & 97 & $\begin{array}{c}137.72 \\
(<0.001)\end{array}$ & \\
\hline
\end{tabular}

*Test of group difference between $4 \mathrm{mg}$ and $8 \mathrm{mg}$ of tocilizumab.

revealed that there was no significant clinical efficacy between the two groups of $4 \mathrm{mg}$ and $8 \mathrm{mg}$ dose of TCZ. So, the type of TCZ as TCZ monotherapy or combination therapy (TCZ + MTX and TCZ + DMARD) was considered with a dose of TCZ as sub-group variables and five subgroups were defined (Fig. S1).

There was a significant difference between the five subgroup in ACR2O $(p=0.02)$. The patient who received 


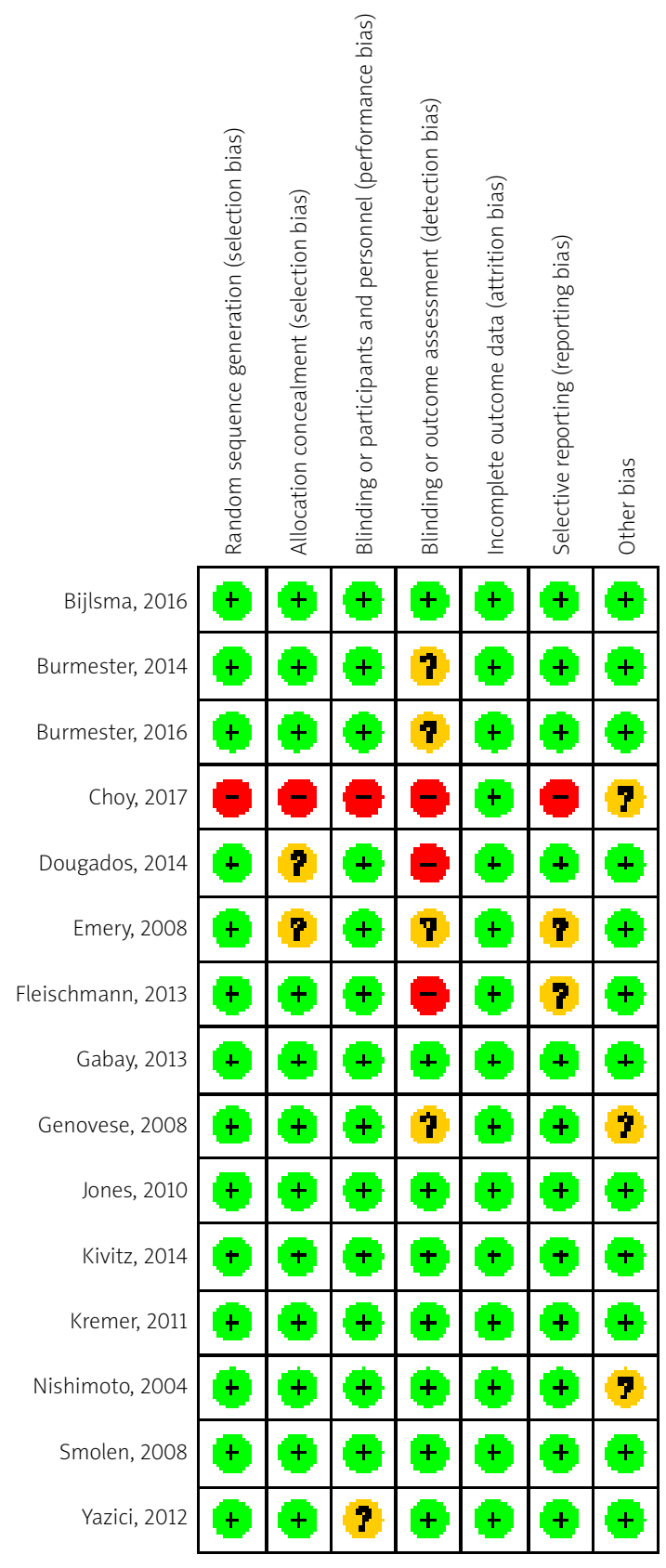

Fig. 2. Risk of bias summary: review authors' judgments about each risk of bias item for each included study.

TCZ monotherapy at $8 \mathrm{mg}$ showed a higher proportion in ACR20 than other subgroups $(\mathrm{OR}=4.60 ; 95 \% \mathrm{Cl}$ : [2.35; 9.0]) (Fig. S1A).

Also, there was a significant difference in ACR50 between the five sub-groups $(p=0.02)$. The patients who were treated with TCZ monotherapy with $4 \mathrm{mg}$ (TCZ $4 \mathrm{mg}$ ) showed a higher proportion of ACR50 than other sub-groups (OR $=4.78 ; 95 \% \mathrm{Cl}$ : $2.69 ; 8.51])$ (Fig. S1B).
Also, TCZ 4 mg had higher efficacy in RA patients to achieve ACR70 compared to other subgroups of treatment $(\mathrm{OR}=8.0 ; 95 \% \mathrm{Cl}$ : [3.23; 19.80]) and there was a significant difference in the proportion of RA patients who achieved ACR70 between defined sub-groups ( $p=0.01$ ) (Fig. S1C).

Assessing the remission as clinical efficacy between the defined subgroups revealed that combination therapy of TCZ (8 mg) + DMARD had the highest proportion of remission in $\mathrm{RA}$ patients $(\mathrm{OR}=23.25 ; 95 \% \mathrm{Cl}$ : [4.32; 125.03]). However, there was no significant difference in the proportion of remission and DAS28 remission in RA patients between the 5 subgroups (Fig. S1D-S1F).

Since the follow-up time may cause the heterogeneity between the results of studies, so it was adjusted in subgroup analysis with dose and type of TCZ. It also could lead to finding the best subgroup of TCZ intervention within which patients achieved the highest improvement and clinical efficacy.

Based on this definition of subgroup analysis, all studies were categorized into 7 sub-groups. There was a significant difference between the seven sub-groups in ACR20/50/70 ( $p<0.001)$ (Table III). Patients who were treated with TCZ $8 \mathrm{mg}$ and followed until 24 weeks showed the highest proportion in ACR20 compared to other sub-groups $(\mathrm{OR}=4.60 ; 95 \% \mathrm{Cl}$ : $[2.35 ; 9.0])$ (Table III).

However, investigation of ACR50/70 (OR = 4.78; 95\% Cl: [2.69, 8.51], OR = 8.0; 95\% Cl: [3.23; 19.80], respectively) showed that patients with RA who were treated with TCZ $4 \mathrm{mg}$ and followed until 24 weeks revealed the highest improvement proportion (Table III).

These results were exactly equal to the result of subgroup analysis based on the type and dose of TCZ. Furthermore, there was a significant difference of remission between the seven sub-groups $(p<0.001)$, it was also found that TCZ (8 mg) + DMARD had the highest proportion of remission in patients with $\mathrm{RA}(\mathrm{OR}=23.25 ; 95 \% \mathrm{Cl}$ [4.32; 125.03]) (Fig. S2).

\section{Adverse events}

All studies reported 86 different side effects. However, 14 of them were held in common between the studies and included in the meta-analysis. The result showed no significant difference in many adverse events between TCZ and the comparator groups.

However, side effects such as skin and subcutaneous tissue disorders (OR $=1.96 ; 95 \% \mathrm{Cl}$ : $[1.47 ; 2.62])$ and eye abnormalities $(\mathrm{OR}=2.37 ; 95 \% \mathrm{Cl}$ : [1.28; 4.41]) were significantly more frequent in the TCZ group in both $4 \mathrm{mg}$ and $8 \mathrm{mg}$ doses than comparator groups.

Also, nervous system disorders for the $8 \mathrm{mg}$ dose $(\mathrm{OR}=1.43 ; 95 \% \mathrm{Cl}:[1.11 ; 1.84])$ and clinical and laboratory abnormalities for $4 \mathrm{mg}(\mathrm{OR}=2.40 ; 95 \% \mathrm{Cl}$ : [1.39; 4.14]), as other adverse events, were significantly higher in the TCZ 
Table III. Subgroup analysis based on dose, type of tocilizumab and follow-up time in the treatment of patients with rheumatoid arthritis

\begin{tabular}{|c|c|c|c|c|c|c|c|c|}
\hline Response & Type & $\begin{array}{l}\text { Dose } \\
\text { [mg] }\end{array}$ & $\begin{array}{c}\text { Time } \\
\text { [week] }\end{array}$ & $n$ & OR $(95 \% \mathrm{Cl})$ & $P^{2}$ & $\begin{array}{c}\chi^{2} \\
(p-\text { value })\end{array}$ & $p$-value ${ }^{\star \star}$ \\
\hline \multirow[t]{12}{*}{ ACR20 } & \multirow[t]{4}{*}{ TCZ } & \multirow[t]{2}{*}{4} & $\leq 24$ & 3 & $3.34^{\star}(1.54 ; 7.24)$ & 75 & $\begin{array}{c}8.23 \\
(0.02)\end{array}$ & \multirow[t]{12}{*}{$<0.001$} \\
\hline & & & $>24$ & - & - & - & - & \\
\hline & & 8 & $\leq 24$ & 7 & $4.60^{\star}(2.35 ; 9.0)$ & 94 & $\begin{array}{c}103.99 \\
(<0.001) \\
\end{array}$ & \\
\hline & & & $>24$ & - & - & - & - & \\
\hline & \multirow[t]{4}{*}{$\mathrm{TCZ}+\mathrm{MTX}$} & \multirow[t]{2}{*}{4} & $\leq 24$ & 1 & $1.37(0.96 ; 1.95)$ & - & - & \\
\hline & & & $>24$ & 1 & $2.60^{*}(1.94 ; 3.49)$ & - & - & \\
\hline & & \multirow[t]{2}{*}{8} & $\leq 24$ & 3 & $0.59(0.27 ; 1.26)$ & 94 & $\begin{array}{c}36.91 \\
(<0.001) \\
\end{array}$ & \\
\hline & & & $>24$ & 2 & $1.06(0.11 ; 10.19)$ & 98 & $\begin{array}{c}64.13 \\
(<0.001)\end{array}$ & \\
\hline & \multirow[t]{4}{*}{$\mathrm{TCZ}+\mathrm{DMARD}$} & \multirow[t]{2}{*}{4} & $\leq 24$ & - & - & - & - & \\
\hline & & & $>24$ & - & - & - & - & \\
\hline & & \multirow[t]{2}{*}{8} & $\leq 24$ & 2 & $2.89^{*}(2.16 ; 3.86)$ & 24 & $\begin{array}{c}1.32 \\
(0.25) \\
\end{array}$ & \\
\hline & & & $>24$ & - & - & - & - & \\
\hline \multirow[t]{12}{*}{ ACR50 } & \multirow[t]{4}{*}{ TCZ } & \multirow[t]{2}{*}{4} & $\leq 24$ & 3 & $4.78^{\star}(2.69 ; 8.51)$ & 21 & $\begin{array}{c}2.55 \\
(0.28)\end{array}$ & \multirow[t]{12}{*}{$<0.001$} \\
\hline & & & $>24$ & - & - & - & - & \\
\hline & & 8 & $\leq 24$ & 6 & $3.96^{\star}(1.82 ; 8.63)$ & 93 & $\begin{array}{c}75.33 \\
(<0.001)\end{array}$ & \\
\hline & & & $>24$ & - & - & - & - & \\
\hline & \multirow[t]{4}{*}{$\mathrm{TCZ}+\mathrm{MTX}$} & \multirow[t]{2}{*}{4} & $\leq 24$ & 1 & $1.21(0.8 ; 1.68)$ & - & - & \\
\hline & & & $>24$ & 1 & $3.04^{*}(2.03 ; 4.53)$ & - & - & \\
\hline & & \multirow[t]{2}{*}{8} & $\leq 24$ & 3 & $0.96(0.39 ; 2.38)$ & 96 & $\begin{array}{c}57.26 \\
(<0.001) \\
\end{array}$ & \\
\hline & & & $>24$ & 2 & $1.26(0.11 ; 14.18)$ & & & \\
\hline & \multirow[t]{4}{*}{ TCZ + DMARD } & \multirow[t]{2}{*}{4} & $\leq 24$ & - & - & - & - & \\
\hline & & & $>24$ & - & - & - & - & \\
\hline & & \multirow[t]{2}{*}{8} & $\leq 24$ & 2 & $4.16^{\star}(2.93 ; 5.92)$ & 11 & $\begin{array}{c}1.13 \\
(0.29)\end{array}$ & \\
\hline & & & $>24$ & - & - & - & - & \\
\hline \multirow[t]{12}{*}{ ACR70 } & \multirow[t]{4}{*}{ TCZ } & \multirow[t]{2}{*}{4} & $\leq 24$ & 3 & $8.0^{\star}(3.23 ; 19.80)$ & 0 & $\begin{array}{c}0.86 \\
(0.65) \\
\end{array}$ & \multirow[t]{12}{*}{$<0.001$} \\
\hline & & & $>24$ & - & - & - & - & \\
\hline & & 8 & $\leq 24$ & 6 & $5.62^{*}(2.17 ; 14.59)$ & 90 & $\begin{array}{c}52.38 \\
(<0.001) \\
\end{array}$ & \\
\hline & & & $>24$ & - & - & - & - & \\
\hline & \multirow[t]{4}{*}{$\mathrm{TCZ}+\mathrm{MTX}$} & \multirow[t]{2}{*}{4} & $\leq 24$ & 1 & $1.56^{*}(1.09 ; 2.24)$ & - & - & \\
\hline & & & $>24$ & 1 & $5.36^{*}(2.48 ; 11.61)$ & - & - & \\
\hline & & 8 & $\leq 24$ & 3 & 1.09 (0.44; 2.72) & 94 & $\begin{array}{c}38.54 \\
(<0.001) \\
\end{array}$ & \\
\hline & & & $>24$ & 2 & $1.50(0.12 ; 18.76)$ & 96 & $\begin{array}{c}28.73 \\
(<0.001) \\
\end{array}$ & \\
\hline & TCZ + DMARD & 4 & $\leq 24$ & - & - & - & - & \\
\hline & & & $>24$ & - & - & - & - & \\
\hline & & 8 & $\leq 24$ & 2 & $7.82(2.19 ; 27.98)$ & 64 & $\begin{array}{c}2.82 \\
(0.09)\end{array}$ & \\
\hline & & & $>24$ & - & - & - & - & \\
\hline
\end{tabular}


Table IV. Adverse events comparing tocilizumab with tocilizumab in different doses

\begin{tabular}{|c|c|c|c|c|c|c|}
\hline Adverse events & $\begin{array}{l}\text { Dose } \\
{[\mathrm{mg}]}\end{array}$ & $n$ & OR $(95 \% \mathrm{Cl})$ & $P^{2}$ & $\begin{array}{c}\chi^{2} \\
\text { (p-value) }\end{array}$ & $p$-value ${ }^{*}$ \\
\hline \multirow[t]{2}{*}{ Headache } & 4 & 2 & $1.68(0.75 ; 3.74)$ & 0 & $\begin{array}{c}0.02 \\
(0.88) \\
\end{array}$ & \multirow[t]{2}{*}{0.97} \\
\hline & 8 & 2 & $1.72(0.77 ; 3.85)$ & 0 & $\begin{array}{l}0.26 \\
(0.88) \\
\end{array}$ & \\
\hline \multirow[t]{2}{*}{$\begin{array}{l}\text { Infections } \\
\text { and infestations (I\&I) }\end{array}$} & 4 & 3 & $1.21(0.89 ; 1.63)$ & 0 & $\begin{array}{c}0.10 \\
(0.95) \\
\end{array}$ & \multirow[t]{2}{*}{0.71} \\
\hline & 8 & 7 & $1.31(0.99 ; 1.72)$ & 59.64 & $\begin{array}{l}14.86 \\
(0.02) \\
\end{array}$ & \\
\hline \multirow[t]{2}{*}{ Gastrointestinal disorders } & 4 & 3 & $1.39(0.78 ; 2.49)$ & 49 & $\begin{array}{l}3.91 \\
(0.14)\end{array}$ & \multirow[t]{2}{*}{0.95} \\
\hline & 8 & 6 & $1.36(0.93 ; 2.0)$ & 62 & $\begin{array}{l}13.14 \\
(0.02)\end{array}$ & \\
\hline \multirow[t]{2}{*}{$\begin{array}{l}\text { Skin and subcutaneous } \\
\text { tissue disorders }\end{array}$} & 4 & 2 & $2.27(1.49 ; 3.84)$ & 0 & $\begin{array}{c}0.7 \\
(0.40) \\
\end{array}$ & \multirow[t]{2}{*}{0.47} \\
\hline & 8 & 5 & $1.83(1.23 ; 2.72)$ & 55 & $\begin{array}{l}8.78 \\
(0.07)\end{array}$ & \\
\hline \multirow{2}{*}{$\begin{array}{l}\text { Musculoskeletal } \\
\text { and connective tissue } \\
\text { disorders }\end{array}$} & 4 & 2 & $0.89(0.61 ; 1.31)$ & 0 & $\begin{array}{c}0.21 \\
(0.65) \\
\end{array}$ & \multirow[t]{2}{*}{0.40} \\
\hline & 8 & 4 & $0.74(0.59 ; 0.93)$ & 0 & $\begin{array}{l}1.52 \\
(0.68) \\
\end{array}$ & \\
\hline \multirow[t]{2}{*}{ Nervous system disorders } & 4 & 2 & $1.05(0.7 ; 1.58)$ & 0 & $\begin{array}{c}0.45 \\
(0.50) \\
\end{array}$ & \multirow[t]{2}{*}{0.21} \\
\hline & 8 & 5 & $1.43(1.11 ; 1.84)$ & 41 & $\begin{array}{c}4.02 \\
(0.40)\end{array}$ & \\
\hline \multirow[t]{2}{*}{ Respiratory disorders } & 4 & 2 & $1.29(0.73 ; 2.29)$ & 0 & $\begin{array}{c}0.81 \\
(0.37) \\
\end{array}$ & \multirow[t]{2}{*}{0.89} \\
\hline & 8 & 4 & $1.35(0.97 ; 1.87)$ & 0 & $\begin{array}{l}2.53 \\
(0.47) \\
\end{array}$ & \\
\hline \multirow[t]{2}{*}{ Injuries and procedural } & 4 & 1 & $0.65(0.29 ; 145)$ & - & - & \multirow{2}{*}{0.26} \\
\hline & 8 & 4 & $1.07(0.76 ; 1.50)$ & 0 & $\begin{array}{c}0.31 \\
(0.96) \\
\end{array}$ & \\
\hline \multirow[t]{2}{*}{$\begin{array}{l}\text { Clinical and laboratory } \\
\text { abnormalities }\end{array}$} & 4 & 2 & $2.40(1.39 ; 4.14)$ & 0 & $\begin{array}{l}<0.001 \\
(0.95)\end{array}$ & \multirow[t]{2}{*}{0.60} \\
\hline & 8 & 5 & $1.89(0.94 ; 3.83)$ & 78 & $\begin{array}{c}17.89 \\
(<0.001)\end{array}$ & \\
\hline \multirow[t]{2}{*}{ Vascular disorders } & 4 & 2 & $1.36(0.43 ; 4.25)$ & 66 & $\begin{array}{l}2.96 \\
(0.09)\end{array}$ & \multirow[t]{2}{*}{0.93} \\
\hline & 8 & 4 & $1.43(1.0 ; 2.03)$ & 0 & $\begin{array}{l}1.65 \\
(0.65) \\
\end{array}$ & \\
\hline \multirow[t]{2}{*}{ Eye disorders } & 4 & 1 & $3.79(1.04 ; 13.85)$ & - & - & \multirow{2}{*}{0.42} \\
\hline & 8 & 2 & $2.06(1.02 ; 4.41)$ & 0 & $\begin{array}{l}0.98 \\
(0.32)\end{array}$ & \\
\hline \multirow[t]{2}{*}{ General disorders } & 4 & 0 & - & - & - & - \\
\hline & 8 & 2 & $2.66(0.25 ; 27.99)$ & 93 & $\begin{array}{c}15.78 \\
(<0.001)\end{array}$ & \\
\hline \multirow{2}{*}{$\begin{array}{l}\text { Myocardial infarction } \\
\text { or acute }\end{array}$} & 4 & 1 & $7.05(0.36 ; 137.07)$ & - & - & \multirow[b]{2}{*}{0.29} \\
\hline & 8 & 2 & $1.11(0.21 ; 5.96)$ & 0 & $\begin{array}{c}0.04 \\
(0.83)\end{array}$ & \\
\hline \multirow[t]{2}{*}{ Hypersensitivity reaction } & 4 & 1 & $3.0(0.12 ; 73.95)$ & - & - & \multirow{2}{*}{0.24} \\
\hline & 8 & 2 & $0.28(0.03 ; 3.08)$ & 0 & $\begin{array}{l}1.49 \\
(0.48)\end{array}$ & \\
\hline
\end{tabular}

${ }^{*}$ Comparison between $4 \mathrm{mg}$ and $8 \mathrm{mg}$ doses. 
group than comparators in doses of $8 \mathrm{mg}$ and $4 \mathrm{mg}$, respectively. Nevertheless, there was no difference in all of the adverse events between $4 \mathrm{mg}$ and $8 \mathrm{mg}$ doses (Table IV).

\section{Discussion}

As far as the evidence may suggest, this is the first meta-analysis to show the safety and efficacy of TCZ in the clinical outcome of patients with RA. The previous limited evidence on analysis of clinical studies on TCZ could suggest benefit for the clinical outcomes of patients with moderate to severe RA not responding to at least one anti-TNF therapy [41, 42].

Although adverse events in patients with RA treated with TCZ, such as abnormal liver function tests (LFTs) and infections, were more frequent than in the comparator groups [42], this therapy was associated with significantly fewer adverse event-related withdrawals [41].

Overall, treatment with TCZ led to statistically significant lower disease activity, as well as significant disease remission, especially in monotherapy form. This finding was consistent with several well-conducted clinical studies [43-46].

The present meta-analysis showed that, although the dose of TCZ did not make a significant difference in the proportion of patient's clinical remission [47], adding other drugs such as methotrexate had a statistically significant impact on disease remission. This finding was in agreement with other clinical evidence showing that adding methotrexate to TCZ was better than TCZ alone [42].

This meta-analysis showed that patients who received TCZ monotherapy ( $8 \mathrm{mg}$ ) had significantly higher clinical remission, a finding which was consistent with previous clinical reports [17, 48]. Moreover, a significantly higher proportion of patients achieved clinical remission at 24-week follow-up. Other prospective studies also reported that patients with RA showed a better clinical response at 24-week follow-up [49-51].

Though former meta-analyses and large prospective cohorts have pointed out serious infection among the most prevalent adverse events associated with TCZ therapy [34, 52-54], our meta-analysis also showed that this adverse event was lower in patients receiving TCZ than in the control group, but the difference did not reach statistical significance.

Interestingly, our meta-analysis revealed that clinical and laboratory abnormalities, skin and subcutaneous tissue disorders, and eye abnormalities were significantly more frequent in patients receiving TCZ than in the control group.

In a single meta-analysis, Teitsma et al. [17] analyzed the efficacy and safety of TCZ as monotherapy or combination therapy reported in randomized controlled trials.
They only searched three major databases, i.e. MEDLINE, EMBASE and Cochrane Central Register of Controlled Trials (CENTRAL), as well as the dose of $8 \mathrm{mg} / \mathrm{kg}$.

Although combination therapy was reported to be marginally superior considering treatment response, increased cost and associated adverse events make TCZ as monotherapy a suitable choice for patients who cannot tolerate conventional DMARDs.

Our pooled analysis was conducted based on a comprehensive search in five major databases - PubMed, Scopus, EMBASE, Web of Sciences (ISI), and Cochrane Library - and 3 recent randomized controlled trials using a total of 2695 subjects (1505 in the intervention group and 1190 in the comparison group) found in the period 2016-2020.

In this context, both previous and our meta-analysis showed a higher significant treatment response. We also compared the treatment response and adverse events considering both different doses and drugs used in combination with TCZ.

\section{Clinical comments}

Based on the evidence provided above plus our findings, we recommend the use of this drug, especially the administration of higher doses in patients with moderate to severe RA as quickly as possible, which may play a more effective role in the treatment and recovery of patients; principally as the European registration authorities recommended administration of $8 \mathrm{mg}$ TCZ straight away without using the dose of $4 \mathrm{mg}$ initially [55].

Also, due to serious complications and clinical and laboratory abnormalities, careful monitoring for laboratory abnormalities is recommended. We also believe that longer follow-up times, particularly after 24 weeks of therapy, are recommendable.

This meta-analysis demonstrated that TCZ can be added to patients using other drugs such as methotrexate and DMARDs; while not surprising, it is worth knowing that TCZ can be used with mentioned drugs as background therapy.

\section{Limitation of the study}

The present meta-analysis has some limitations that should be addressed. Diverse treatment regimens, various TCZ dosage and frequency, as well as different comparators, were applied in the selected studies.

\section{Conclusions}

This systematic review and meta-analysis suggest that the combination therapy of TCZ with other drugs such as methotrexate and DMARDs has been studied for various clinical effects with slighthly was superior 
to monotherapy, therefore presented meta-analysis has been studied.

Although the data are promising, long-term performance and safety data need to be fully identified, as well as the risks and benefits of TCZ, especially appropriate timing, dosage and regimen.

The authors declare no conflict of interest.

\section{References}

1. Guo Q, Wang Y, Xu D, Nossent J, et al. Rheumatoid arthritis: pathological mechanisms and modern pharmacologic therapies. Bone Res 2018; 6: 15, DOI: 10.1038/s41413-018-0016-9.

2. Deane KD, Demoruelle MK, Kelmenson LB, et al. Genetic and environmental risk factors for rheumatoid arthritis Best Pract Res Clin Rheumatol 2017; 31: 3-18, DOI: 10.1016/ j.berh.2017.08.003.

3. Mori H, Sawada T, Nishiyama S, et al. Influence of seasonal changes on disease activity and distribution of affected joints in rheumatoid arthritis. BMC Musculoskelet Disord 2019; 20: 30, DOI: 10.1186/s12891-019-2418-2.

4. Croitoru AE, Dogaru G, Man TC, et al. Perceived influence of weather conditions on rheumatic pain in Romania. Advances in Meteorology 2019; 2019: 9187105, DOI: 10.1155/2019/9187105.

5. Heidari B. Rheumatoid Arthritis: early diagnosis and treatment outcomes. Caspian J Intern Med 2011; 2: 161-170.

6. Molokhia M, McKeigue P. Risk for rheumatic disease in relation to ethnicity and admixture. Arthritis Res 2000; 2: 115-125, DOI: 10.1186/ar76.

7. van Vollenhoven RF. Sex differences in rheumatoid arthritis: more than meets the eye. BMC Med 2009; 7: 12, DOI: 10.1186/1741-7015-7-12.

8. Davis JM, 3rd, Matteson EL, American College of Rheumatology. My treatment approach to rheumatoid arthritis. Mayo Clin Proc 2012; 87: 659-673, DOI: 10.1016/j.mayocp.2012.03.011.

9. Crofford LJ. Use of NSAIDs in treating patients with arthritis. Arthritis Res Ther 2013; 15 Suppl 3(Suppl 3): S2, DOI: 10.1186/ ar4174.

10. Zarghi A, Arfaei S. Selective COX-2 inhibitors: a review of their structure-activity relationships. Iran J Pharm Res 2011; 10: 655-683.

11. van Laar M, Pergolizzi JV Jr, Mellinghoff HU, et al. Pain treatment in arthritis-related pain: beyond NSAIDs. Open Rheumatol J 2012; 6: 320-330, DOI: 10.2174/1874312901206010320.

12. Kay J, Upchurch KS. ACR/EULAR 2010 rheumatoid arthritis classification criteria. Rheumatology (Oxford) 2012; 51 (Suppl 6): vi5-vi9, DOI: 10.1093/rheumatology/kes279.

13. Aletaha D, Neogi T, Silman AJ, et al. 2010 Rheumatoid arthritis classification criteria: an American College of Rheumatology/ European League Against Rheumatism collaborative initiative. Arthritis Rheum 2010; 62: 2569-2581, DOI: 10.1002/art.27584.

14. Smolen JS, Aletaha D, Barton A, et al. Rheumatoid arthritis. Nat Rev Dis Primers 2018; 4: 18001, DOI: 10.1038/nrdp.2018.1.

15. Sheppard M, Laskou F, Stapleton PP, et al. Tocilizumab (actemra). Hum Vaccin Immunothe 2017; 13: 1972-1988, DOI: 10.1080/21645515.2017.1316909.
16. Tanaka T, Narazaki M, Kishimoto T. IL-6 in inflammation, immunity, and disease. Cold Spring Harb Perspect Biol 2014; 6: a016295-a016295, DOI: 10.1101/cshperspect.a016295.

17. Teitsma XM, Marijnissen AKA, Bijlsma JW, et al. Tocilizumab as monotherapy or combination therapy for treating active rheumatoid arthritis: a meta-analysis of efficacy and safety reported in randomized controlled trials. Arthritis Res Ther 2016; 18: 211, DOI: 10.1186/s13075-016-1108-9.

18. Biggioggero M, Crotti C, Becciolini A, Favalli EG. Tocilizumab in the treatment of rheumatoid arthritis: an evidence-based review and patient selection. Drug Des Devel Ther 2019; 13: 57-70, DOI: 10.2147/DDDT.S150580.

19. Rubbert-Roth A, Furst DE, Nebesky JM, et al. A Review of recent advances using tocilizumab in the treatment of rheumatic diseases. Rheumatol Ther 2018; 5: 21-42, DOI: 10.1007/ s40744-018-0102-x.

20. Moher D, Shamseer L, Clarke M, et al. Preferred reporting items for systematic review and meta-analysis protocols (PRISMA-P) 2015 statement. Syst Rev 2015; 4: 1, DOI: 10.1186/2046-4053-4-1.

21. Higgins JPT, Thomas J, Chandler J, et al. Cochrane handbook for systematic reviews of interventions. John Wiley \& Sons, Chichester 2019.

22. Higgins JP, Altman DG, Gøtzsche PC,et al. The Cochrane Collaboration's tool for assessing risk of bias in randomised trials. BMJ 2011; 343: d5928, DOI: 10.1136/bmj.d5928.

23. Higgins JP, Thompson SG, Deeks JJ, Altman DG. Measuring inconsistency in meta-analyses. BMJ 2003; 327: 557-560, DOI: 10.1136/bmj.327.7414.557.

24. DerSimonian R, Laird N. Meta-analysis in clinical trials. Control Clin Trials 1986; 7: 177-188, DOI: 10.1016/0197-2456(86)90046-2.

25. Mantel N, Haenszel W. Statistical aspects of the analysis of data from retrospective studies of disease. J Natl Cancer Inst 1959; 22: 719-748.

26. Gabay C, Emery P, van Vollenhoven R, et al. Tocilizumab monotherapy versus adalimumab monotherapy for treatment of rheumatoid arthritis (ADACTA): a randomised, double-blind, controlled phase 4 trial. Lancet 2013, 381: 1541-1550, DOI: 10.1016/S0140-6736(13)60250-0.

27. Bijlsma JWJ, Welsing PMJ, Woodworth TG, et al. Early rheumatoid arthritis treated with tocilizumab, methotrexate, or their combination (U-Act-Early): a multicentre, randomised, double-blind, double-dummy, strategy trial. Lancet 2016; 388: 343-355, DOI: 10.1016/S0140-6736(16)30363-4.

28. Burmester GR, Rigby WF, van Vollenhoven RF, et al. Tocilizumab in early progressive rheumatoid arthritis: FUNCTION, a randomised controlled trial. Ann Rheum Dis 2016, 75: 1081-1091, DOI: 10.1136/annrheumdis-2015-207628.

29. Burmester GR, Rubbert-Roth A, Cantagrel A, et al. A randomised, double-blind, parallel-group study of the safety and efficacy of subcutaneous tocilizumab versus intravenous tocilizumab in combination with traditional disease-modifying antirheumatic drugs in patients with moderate to severe rheumatoid arthritis (SUMMACTA study). Ann Rheum Dis 2014, 73: 69-74, DOI: 10.1136/annrheumdis-2013-203523.

30. Choy EH, Bernasconi C, Aassi M, et al. Treatment of rheumatoid arthritis with anti-tumor necrosis factor or tocilizumab therapy as first biologic agent in a global comparative observational study. Arthritis Care Res (Hoboken) 2017; 69: 14841494, DOI: 10.1002/acr.23303.

31. Dougados M, Kissel K, Conaghan PG, et al. Clinical, radiographic and immunogenic effects after 1 year of tocilizum- 
ab-based treatment strategies in rheumatoid arthritis: the ACT-RAY study. Ann Rheum Dis 2014; 73: 803-809, DOI: 10.1136/annrheumdis-2013-204761.

32. Emery P, Keystone E, Tony HP, et al. IL-6 receptor inhibition with tocilizumab improves treatment outcomes in patients with rheumatoid arthritis refractory to anti-tumour necrosis factor biologicals: results from a 24-week multicentre randomised placebo-controlled trial. Ann Rheum Dis 2008; 67 : 1516-1523, DOI: 10.1136/ard.2008.092932.

33. Genovese MC, McKay JD, Nasonov EL, et al. Interleukin-6 receptor inhibition with tocilizumab reduces disease activity in rheumatoid arthritis with inadequate response to diseasemodifying antirheumatic drugs: the tocilizumab in combination with traditional disease-modifying antirheumatic drug therapy study. Arthritis Rheum 2008; 58: 2968-2980, DOI: 10.1136/ard.2008.092932.

34. Jones G, Sebba A, Gu J, et al. Comparison of tocilizumab monotherapy versus methotrexate monotherapy in patients with moderate to severe rheumatoid arthritis: the AMBITION study. Ann Rheum Dis 2010; 69: 88-96, DOI: 10.1136/ard. 2008.105197

35. Kivitz A, Olech E, Borofsky M, et al. Subcutaneous tocilizumab versus placebo in combination with disease-modifying antirheumatic drugs in patients with rheumatoid arthritis. Arthritis Care Res (Hoboken) 2014; 66:1 653-1661, DOI: 10.1002/ acr.22384.

36. Kremer JM, Blanco R, Brzosko $M$, et al. Tocilizumab inhibits structural joint damage in rheumatoid arthritis patients with inadequate responses to methotrexate: results from the double-blind treatment phase of a randomized placebo-controlled trial of tocilizumab safety and prevention of structural joint damage at one year. Arthritis Rheum 2011; 63: 609-621, DOI: 10.1002/art.30158.

37. Nishimoto N, Yoshizaki K, Miyasaka N, et al. Treatment of rheumatoid arthritis with humanized anti-interleukin- 6 receptor antibody: a multicenter, double-blind, placebo-controlled trial. Arthritis Rheum 2004; 50: 1761-1769, DOI: 10.1002/ art.20303.

38. Smolen JS, Beaulieu A, Rubbert-Roth A, et al. Effect of interleukin-6 receptor inhibition with tocilizumab in patients with rheumatoid arthritis (OPTION study): a double-blind, placebocontrolled, randomised trial. Lancet 2008; 371: 987-997, DOI: 10.1016/S0140-6736(08)60453-5

39. Yazici Y, Curtis JR, Ince A, et al. Efficacy of tocilizumab in patients with moderate to severe active rheumatoid arthritis and a previous inadequate response to disease-modifying antirheumatic drugs: the ROSE study. Ann Rheum Dis 2012; 71: 198-205, DOI: 10.1136/ard.2010.148700.

40. Fleischmann RM, Halland AM, Brzosko $M$, et al. Tocilizumab inhibits structural joint damage and improves physical function in patients with rheumatoid arthritis and inadequate responses to methotrexate: LITHE study 2-year results. J Rheumatol 2013; 40: 113-126, DOI: 10.3899/jrheum.120447.

41. González-Vacarezza N, Alemán A, González G, Pérez A. Ritu ximab and tocilizumab for the treatment of rheumatoid arthritis. Int J Technol Assess Health Care 2014; 30: 282-288, DOI: 10.1017/S0266462314000221.

42. Navarro G, Taroumian S, Barroso N, et al. Tocilizumab in rheumatoid arthritis: a meta-analysis of efficacy and selected clinical conundrums. Semin Arthritis Rheum 2014; 43: 458-469, DOI: 10.1016/j.semarthrit.2013.08.001.
43. Kaneko Y, Kato M, Tanaka Y, I et al. Tocilizumab discontinuation after attaining remission in patients with rheumatoid arthritis who were treated with tocilizumab alone or in combination with methotrexate: results from a prospective randomised controlled study (the second year of the SURPRISE study). Ann Rheum Dis 2018; 77: 1268-1275, DOI: 10.1136/ annrheumdis-2018-213416.

44. Scott LJ. Tocilizumab: A review in rheumatoid arthritis. Drugs 2017; 77: 1865-1879, DOI: 10.1007/s40265-017-0829-7.

45. Nishimoto N, Amano K, Hirabayashi Y, et al. Drug free REmission/low disease activity after cessation of tocilizumab (actemra) Monotherapy (DREAM) study. Modern Rheumatol 2014, 24: 17-25, DOI: 10.3109/14397595.2013.854079.

46. Cappelli LC, Palmer J, Kremer J, Bingham CO 3rd. Tocilizumab treatment leads to improvement in disease activity regardless of CCP status in rheumatoid arthritis. Semin Arthritis Rheum 2017; 47: 165-169, DOI: 10.1016/j.semarthrit.2017.03.024.

47. Haraoui B, Jamal S, Ahluwalia V, et al. Real-world tocilizumab use in patients with rheumatoid arthritis in Canada: 12-month results from an observational, noninterventional study. Rheumatol Ther 2018; 5: 551-565, DOI: 10.1007/s40744-018-0130-6.

48. Jones G, Wallace T, Mclntosh MJ, et al. Five-year efficacy and safety of tocilizumab monotherapy in patients with rheumatoid arthritis who were methotrexate- and biologic-naive or free of methotrexate for 6 months: the AMBITION study. J Rheumatol 2017; 44: 142-146, DOI: 10.3899/jrheum.160287.

49. Bykerk VP, Östör AJK, Alvaro-Gracia J, et al. Long-term safety and effectiveness of tocilizumab in patients with rheumatoid arthritis and inadequate responses to csDMARDs and/or TNF inhibitors: an open-label study close to clinical practice. Clinical Rheumatology 2019; 38: 2411-2421, DOI: 10.1007/s10067-01904535-z.

50. Huizinga TWJ, Conaghan PG, Martin-Mola E, et al. Clinical and radiographic outcomes at 2 years and the effect of tocilizumab discontinuation following sustained remission in the second and third year of the ACT-RAY study. Ann Rheum Dis 2015; 74: 35-43, DOI: 10.1136/annrheumdis-2014-205752.

51. Romão VC, Santos MJ, Polido-Pereira J, et al. Comparative effectiveness of tocilizumab and tnf inhibitors in rheumatoid arthritis patients: data from the rheumatic diseases Portuguese register, Reuma.pt. Biomed Res Int 2015, 2015: 279890, DOI: 10.1155/2015/279890.

52. Yazici Y, Curtis JR, Ince A, et al. Efficacy of tocilizumab in patients with moderate to severe active rheumatoid arthritis and a previous inadequate response to disease-modifying antirheumatic drugs: the ROSE study. Ann Rheum Dis 2012; 71: 198-205, DOI: 10.1136/ard.2010.148700.

53. Navarro-Millán I, Singh JA, Curtis JR. Systematic review of tocilizumab for rheumatoid arthritis: a new biologic agent targeting the interleukin-6 receptor. Clin Ther 2012; 34: 788-802. e783, DOI: 10.1016/j.clinthera.2012.02.014.

54. Maini RN, Taylor PC, Szechinski J, et al. Double-blind randomized controlled clinical trial of the interleukin- 6 receptor antagonist, tocilizumab, in European patients with rheumatoid arthritis who had an incomplete response to methotrexate. Arthritis Rheum 2006; 54: 2817-2829, DOI: 10.1002/art.22033.

55. Pappas DA, John A, Curtis JR, et al. Dosing of Intravenous tocilizumab in a real-world setting of rheumatoid arthritis: analyses from the Corrona registry. Rheumatol Ther 2016; 3 : 103-115, DOI: 10.1007/s40744-016-0028-0. 